\title{
CERTAIN SUBCLASSES OF BI-UNIVALENT FUNCTIONS SATISFYING SUBORDINATE CONDITIONS
}

\section{ERHAN DENIZ}

Abstract. In this paper, we introduce and investigate each of the following subclasses:

$$
\begin{gathered}
\mathscr{S}_{\Sigma}(\lambda, \gamma ; \varphi), \mathscr{H}_{\Sigma}(\alpha), \mathscr{R}_{\Sigma}(\eta, \gamma ; \varphi) \text { and } \mathscr{B}_{\Sigma}(\mu ; \varphi) \\
(0 \leqslant \lambda \leqslant 1 ; \gamma \in \mathbb{C} \backslash\{0\} ; \alpha \in \mathbb{C} ; 0 \leqslant \eta<1 ; \mu \geqslant 0)
\end{gathered}
$$

of bi-univalent functions, $\varphi$ is an analytic function with positive real part in the unit disk $\mathbb{D}$, satisfying $\varphi(0)=1, \varphi^{\prime}(0)>0$, and $\varphi(\mathbb{D})$ is symmetric with respect to the real axis. We obtain coefficient bounds involving the Taylor-Maclaurin coefficients $\left|a_{2}\right|$ and $\left|a_{3}\right|$ of the function $f$ when $f$ is in these classes. The various results, which are presented in this paper, would generalize and improve those in related works of several earlier authors.

Mathematics subject classification (2010): 30C45; Secondary 30C50, 30C80.

Keywords and phrases: Univalent functions, bi-univalent functions, bi-starlike and bi-convex functions of complex order, bi-Bazilevič functions, subordination.

\section{REFERENCES}

[1] R. M. Ali, S. K. Lee, V. Ravichandran and S. Supramaniam, Coefficient estimates for biunivalent Ma-Minda starlike and convex functions, Appl. Math. Lett. 25 (3) (2012), 344-351.

[2] I. E. BAZILEVIČ, On a case of integrability in quadratures of the Loewner-Kufarev equation, Mat. Sb. N.S. 37 (79) (1955), 471-476.

[3] D. A. Brannan And T. S. TAha, On some classes of bi-univalent functions, Studia Univ. BabeşBolyai Math. 31 (2) (1986), 70-77.

[4] D. A. Brannan And J. G. Clunie, Aspects of contemporary complex analysis (Proceedings of the NATO Advanced Study Institute held at the University of Durham, Durham, July 120, 1979), Academic Press, London and New York, (1980).

[5] P. L. DuREN, Univalent Functions, Grundlehren der Mathematischen Wissenschaften, 259, Springer, New York, 1983.

[6] B. A. Frasin And M. K. Aouf, New subclasses of bi-univalent functions, Appl. Math. Lett. 24 (9) (2011), 1569-1573

[7] M. Lewin, On a coefficient problem for bi-univalent functions, Proc. Amer. Math. Soc. 18 (1967), 63-68.

[8] W. C. MA AND D. Minda, A unified treatment of some special classes of univalent functions, in Proceedings of the Conference on Complex Analysis (Tianjin, 1992), 157-169, Conf. Proc. Lecture Notes Anal. I Int. Press, Cambridge, MA.

[9] E. NeTANYAHU, The minimal distance of the image boundary from the origin and the second coeffcient of a univalent function in $|z|<1$, Arch. Rational Mech. Anal. 32 (1969), 100-112.

[10] N. N. PASCU AND D. RĂDUCANU, Generalized means and generalized convexity, Seminar of Geometric Function Theory, Preprint 3 (1993), 95-98.

[11] V. Ravichandran, A. Gangadharan And M. Darus, Fekete-Szegö inequality for certain class of Bazilevič functions, Far East J. Math. Sci. (FJMS) 15 (2) (2004), 171-180.

[12] R. Singh, On Bazilevič functions, Proc. Amer. Math. Soc. 38 (1973), 261-271.

[13] H. M. Srivastava, A. K. Mishra and P. Gochhayat, Certain subclasses of analytic and biunivalent functions, Appl. Math. Lett. 23 (10) (2010), 1188-1192. 
[14] H. M. SRivastava, O. Altintaş And S. K. Serenbay, Coefficient bounds for certain subclasses of starlike functions of complex order, Appl. Math. Lett. 24 (2011), 1359-1363.

[15] A. Swaminathan, Sufficient conditions for hypergeometric functions to be in a certain class of analytic functions, Comput. Math. Appl. 59 (2010), 1578-1583.

[16] T. S. TAHA, Topics in Univalent Function Theory, Ph. D. Thesis, University of London, 1981.

[17] Q.-H. XU, Y. C. GUI AND H. M. SRIVASTAVA, Coefficient estimates for certain subclasses of analytic functions of complex order, Taiwanese J. Math. 15 (5) (2011), 2377-2386.

[18] Q.-H. XU, Y.-C. GUI AND H. M. SRIVASTAVA, Coefficient estimates for a certain subclass of analytic and bi-univalent functions, Appl. Math. Lett. 25 (2012) 990-994. 